\title{
Examining Within-Country Variation of Maternity Costs in the Context of a Multicountry, Multicentre Randomised Controlled Trial
}

\author{
Guy Hutton, ${ }_{1}^{1}$ Julia Fox-Rushby, ${ }^{2}$ Miranda Mugford, ${ }^{3}$ Jadsada Thinkhamrop, ${ }^{4}$ Bandit Thinkhamrop, ${ }^{5}$ Ana \\ Maria Galvez ${ }^{6}$ and Manuel Alvarez \\ 1 Swiss Centre for International Health, Swiss Tropical Institute, Basel, Switzerland \\ 2 Health Economics Research Group, Brunel University, Uxbridge, Middlesex, UK \\ 3 School of Medicine, Health Policy and Practice, University of East Anglia, Norwich, UK \\ 4 Department of Obstetrics and Gynecology, Khon Kaen University, Khon Kaen, Thailand \\ 5 Department of Biostatistics and Demography, Khon Kaen University, Khon Kaen, Thailand \\ 6 National School of Public Health, Havana, Cuba \\ 7 Ministry of Public Health, Havana, Cuba
}

\begin{abstract}
Understanding why healthcare costs vary between patients and between health facilities is important in guiding health policy decisions as well as in research. However, there is no comprehensive framework that analysts commonly use for expressing and examining causes of cost variation in the field of healthcare. The aim of this study is to better understand the size and causes of within-country healthcare cost variation, through presenting evidence for size and sources of such variations for two countries (Cuba and Thailand) in the context of a randomised controlled trial on antenatal care. The article separates total costs into their two components: unit costs and health service use. Unit costs are further separated into input quantity per patient visit or day, and the prices of these resources. The results show that the main determinant of average cost is the staffing pattern and productivity, whereas the main determinants of health service use include the model of antenatal care being practised and the risk status and illnesses suffered by patients. However, variations in inpatient health service use between facilities are largely related to unexplainable variations in practice between facilities, irrespective of the trial arm. In conclusion, cost variations have important implications for the design of clinical trials and for policy makers using evidence from trials in planning health services and budgets.
\end{abstract}

Understanding why healthcare costs vary is important for several reasons. Analysts may wish to understand why cost-effectiveness ratios vary between two or more settings when applying cost-effectiveness results outside the original study settings. ${ }^{[1]}$ Managers and policy makers may wish to assess cost implications of a new healthcare intervention in setting prices and budgets, for example when using programme budgeting and marginal analysis. ${ }^{[2]}$ Even within a single study, such as a multicentre randomised controlled trial (RCT), analysts may wish to extrapolate costs between sites to save on research costs. ${ }^{[3]}$ In other words, cost variation is a concern both for researchers, in collecting, presenting and interpreting cost data, and for planners who use the cost information.

Despite the recognition of the importance of understanding cost variation, commentators have pointed out that, in practice, costs and cost-effectiveness ratios are often generalised between healthcare settings or estimated on the basis of inadequate data. ${ }^{[1,3-7]}$ Generalisations are therefore made without fully understanding how the differences between setting will influence cost effectiveness. Also, reviews have found that cost calculations are often not 
described and costs are not presented in disaggregated form, as is needed to allow analysts to assess the generalisability of economic evaluation results to other settings. ${ }^{[8-11]}$ Furthermore, the concern expressed about country-to-country variations in costs and cost-effectiveness ratios ${ }^{[1,3]}$ should be supplemented with a concern for a lack of within-country generalisability, due to variations also found at that level. ${ }^{[7,12]}$

Consequently, it is surprising that there has been no comprehensive framework developed that analysts can commonly use for expressing and examining causes of cost variation in the field of healthcare. There are methodologies and tools, such as data envelopment analysis and regression analysis, that contribute to a partial understanding of costs and cost variation. Recently, some progress has been made towards a framework. ${ }^{[13-15]}$ However, opportunities for analysing cost variation are not utilised, either because it is of secondary importance compared with the primary aim of most studies measuring cost effectiveness or because studies conducted in multiple settings are not designed to allow detailed analysis and comparison of costs. To illustrate this latter point, a recent search on PubMed ${ }^{\circledR}$ for multinational trials with economic evaluations revealed 12 such studies, of which:

- six studies measured unit costs or used reimbursement prices in all countries participating in the trial; ${ }^{[3,16-19]}$

- three studies measured unit costs or used reimbursement prices in some countries and generalised these to other study countries; ${ }^{[20-22]}$

- three studies measured unit costs or used reimbursement prices from one country and generalised to all other countries in the trial. ${ }^{[23-25]}$

In all 12 studies, different costing methodologies or data sources had to be used in the participating countries because of the diversity in the settings, the difficulties in conducting research, or the limited time or research funds. This suggests a lost opportunity for analysing the causes of cost variation between as well as within countries and for developing a framework for the comprehensive analysis of costs.

\section{The Study}

The cost analysis presented in this article is based on one of the multinational RCTs with economic evaluations that was found on PubMed ${ }^{\circledR}:{ }^{[19]}$ a study evaluating the cost effectiveness of a new antenatal care model in four middle-income countries. The study compared clusters of at least six randomised health facilities per trial arm and per country. ${ }^{[26]}$ The economic evaluation prospectively measured detailed costs in all randomised units of health clinics in two of the study countries (Cuba and Thailand), thus allowing for detailed cost comparisons and analyses. ${ }^{[27]}$

\section{Cost Typology and Classification}

When talking about cost variation, it is important to be clear about what is meant by 'cost' ${ }^{[28-32]}$ Six different interpretations of 'cost' were distinguished for the purpose of this study and are defined in table I: prices, input quantity, unit cost, health service use, case cost, total cost and incremental cost. The distinction between the components of these different types of cost is important when making generalisations about, or comparisons of, cost. Such a distinction enables differences in each component to be compared and analysed separately. Figure 1 illustrates how the different components of cost are aggregated to estimate incremental costs.

\section{Study Aims and Objectives}

The overall aim of this study is to better understand the size and causes of within-country healthcare cost variation. The study examines the determinants of cost by analysing separately the various components of aggregate cost, using the definitions of cost in table I. Specifically, the study aims to:

- present evidence for within-country cost variations for Cuba and Thailand, for different levels of cost (unit costs, health service use and case cost), using costs gathered from the WHO antenatal care trial; ${ }^{[19]}$

- examine the causes of cost variation at these levels in both countries;

- determine the principle causes of within-country cost variation in these settings, and the implications for health policy;

- draw conclusions on the usefulness of the framework adopted for analysing cost variation.

\section{Methods}

\section{The WHO Antenatal Care Trial}

The WHO antenatal care trial was designed as a multicentre, multinational cluster randomised controlled trial, with study sites in Argentina, Cuba, Saudi Arabia and Thailand. The trial design and intervention have been described fully elsewhere. ${ }^{[26]}$ One important aim of the new antenatal programme was to reduce the number of antenatal visits in low-risk pregnancies to four visits. In each country, a minimum of six health facilities providing the new antenatal care programme were compared with the current model 
Table I. Definition of cost terms

\begin{tabular}{|c|c|}
\hline Term & Definition \\
\hline Price & $\begin{array}{l}\text { The price of a resource. For example, the market value for a doctor's hour or for a single item of equipment. Two } \\
\text { alternative prices are distinguished: economic price and financial price }\end{array}$ \\
\hline economic price & The opportunity lost because of the use of a resource in an activity (also called opportunity cost) \\
\hline financial price & The money paid for a resource \\
\hline Input quantity & $\begin{array}{l}\text { Quantity of the resource input, in physical units. Types of resource input include 'staff', 'equipment', 'materials', } \\
\text { 'drugs', 'utilities' and 'land and buildings' }\end{array}$ \\
\hline Health service use & $\begin{array}{l}\text { Types of health service include outpatient visits, inpatient days or admissions, number of operations and laboratory } \\
\text { tests. These can be expressed as a 'throughput' for a particular type of patient or population, and for a specified } \\
\text { time period }\end{array}$ \\
\hline Unit cost of health services & This can be expressed as average cost or marginal cost \\
\hline average cost & This includes all resource inputs into the healthcare process \\
\hline marginal cost & This includes only resource inputs that change with one unit of production \\
\hline Case cost & $\begin{array}{l}\text { The cost for a single patient for a specified illness and/or over a specified time period. For example, the costs of a } \\
\text { surgical case may include all outpatient visits, inpatient days and surgical procedures associated with the surgery }\end{array}$ \\
\hline Total cost & $\begin{array}{l}\text { The cost of health services for a defined population, health programme or health facility, and over a given time } \\
\text { period }\end{array}$ \\
\hline Incremental cost & $\begin{array}{l}\text { The difference between the case cost of two or more competing and mutually exclusive options, using either } \\
\text { average costs or marginal costs, to reflect the long-run and short-run incremental costs, respectively }\end{array}$ \\
\hline
\end{tabular}

of care. The trial results showed that no significant difference was found between the new model of antenatal care and the traditional package. ${ }^{[19]}$

\section{Economic Evaluation alongside the Antenatal Care Tria}

The economic evaluation was planned as a cost-minimisation analysis, and as a cost-effectiveness analysis in the event that important differences in effects were found. ${ }^{[27]}$ Costs were measured from the viewpoint of health providers and the women patients. The economic evaluation measured the unit costs of providing antenatal, delivery and postpartum care, including neonatal specialist care. A full costing study was conducted in Cuba and Thailand from the beginning of the trial, ${ }^{[33,34]}$ and less intensive economic data collection took place in Argentina and Saudi Arabia at a later stage. ${ }^{[35,36]} \mathrm{A}$ top-down costing methodology was used to estimate health service unit costs (average cost, marginal cost) on a monthly basis for 8 consecutive months in Cuba and 15 consecutive months in Thailand. The unit costs were combined with health service use data collected within the WHO trial, to calculate a woman-specific cost per pregnancy (CPP) for all women meeting the trial criteria. CPP was calculated for each woman and averaged for each randomised health facility and both trial arms. CPP was calculated using both average cost (ACPP) and marginal cost (MCPP), the latter being approximated using drug and material costs only. For presentation, cost data were converted from local currencies to \$US prices using nominal exchange rates at the mid-point of the trial: 8 January 1998.

\section{Cost Analysis}

Variations in three types of cost were analysed: health service use, unit costs of health services and cost per pregnancy.

1. Health service use differences: data were collected and compared for demand factors (related to the patient) and supply factors (related to the provider) that were hypothesised to affect health service use. In addition to data available from the health service costing studies, data were also used from parallel studies in each country, including studies on patient $\operatorname{costs}^{[33,34]}$ and studies on patient and provider satisfaction with the models of antenatal care. [37]

2. Unit cost differences: table II summarises the methods used to explain unit cost variations along with the hypothesised impact of different factors on unit cost. Five main technical sources of within-country cost variation were examined: x-efficiency, returns to the variable factor, economies of scale, input mix (including quality aspects) and patient case mix. In addition, differences in costing methodology and uncertainty within each country were examined qualitatively. These sources of cost variation were examined using a variety of techniques, including sensitivity analysis, input-output analysis, cost profile analysis, efficiency scoring, 

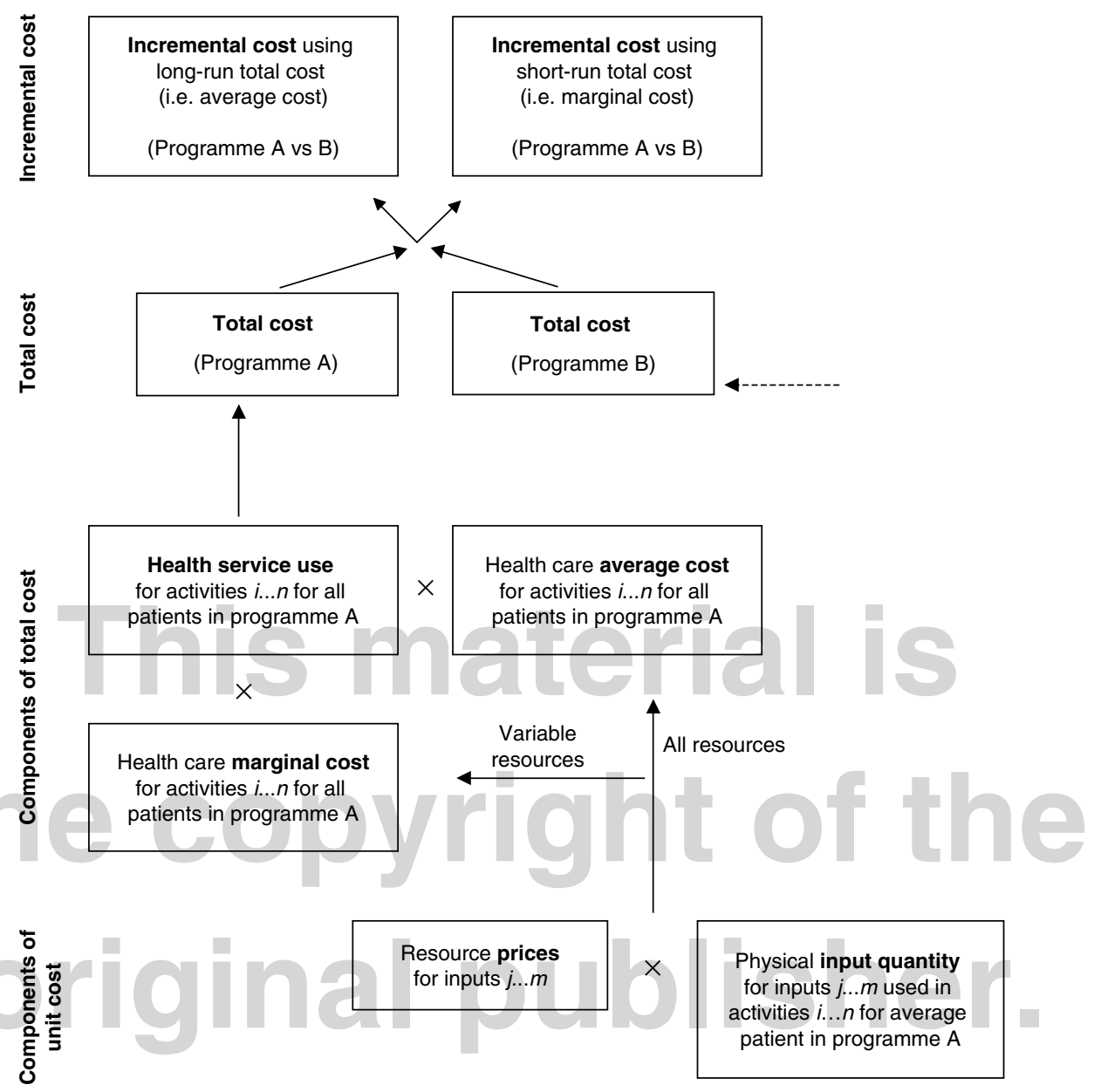

Fig. 1. Relationship between different types of 'cost'.

scatter plots and the Pearson correlation coefficient to determine two-way relationships.

3. Case cost differences: first, case cost differences were analysed by graphing CPP against health service use rates and unit costs to identify which components were most responsible for CPP variations. Second, CPP for different case mixes (risk factors and illness events) were compared to see which factors predicted CPP using bivariate analysis.

\section{Results}

\section{Explaining Inter-Facility Variation in Outpatient Antenatal Attendance}

Table III shows the rates of health services use, averaged by randomised health facility in Cuba and Thailand. Various explana- tory factors for different antenatal visit rates between intervention and control trial arms were examined. Although most of these factors were found to vary insignificantly between trial arms, some factors were found to vary more significantly, including:

1. The intervention being tested, relating to:

(a) Guidance to intervention arm facility healthcare providers to follow an antenatal visit schedule, advocating four visits for lowrisk pregnancies;

(b) Medication cost per visit in the intervention arm;

(c) Return rates for women attending intervention arm clinics, as syphilis tests were done on the spot in the intervention clinics in Cuba;

(d) Average waiting times at intervention arm antenatal clinics, as these were lower in Thailand. 
2. Risk rates observed between trial arms, relating to, for example, outcomes of previous pregnancies and reproductive health history.

3. Population behaviour not related to the intervention, such as earlier antenatal clinic attendance in the control arm in Thailand.

It is also important to note that the women's and providers' satisfaction survey showed that overall (in the four trial countries) women were no less satisfied when having fewer visits. ${ }^{[37,38]}$ This finding suggests that most women would not seek additional antenatal visits in the intervention arm in response to a less intensive antenatal schedule.

\section{Explaining Inter-Facility Variation in Outpatient Unit Costs}

For unit costs, there was no systematic difference found between trial arms in either country. However, there was considerable inter-facility variation in unit costs. Figure 2 shows a clear, though not perfect, negative correlation between unit costs and visits per full time equivalent (FTE) staff member in Cuba. This was partially confirmed by a nonsignificant $(p>0.05)$ Pearson correlation coefficient of -0.554 . In most cases, a high average cost is associated with low visits per FTE, and vice versa. This was found to be true for the unit costs of inpatient care as well. When average costs in Cuba were recalculated using the visits per FTE of the most efficient policlinic (policlinic $\mathrm{H}$ ), some convergence $(\mathrm{L}$, $\mathrm{M}, \mathrm{F})$ as well as divergence $(\mathrm{G})$ is observed. The presence of economies of scale is suggested in Cuba with a Pearson correlation coefficient of $-0.851(\mathrm{p}<0.01)$ between unit cost and policlinic patient capacity. Finally, significant variation is found between policlinics in the contribution of non-staff inputs to average cost. For example, these range from \$US0.04 to \$US0.26 for equipment, \$US0.08 to \$US0.33 for materials and \$US3.02 to \$US6.77 for drugs.

In Thailand, unit cost correlation with the efficiency measure (visits per FTE) was nonsignificant ( $\mathrm{p}=0.054$ ), although the correlation coefficient of 0.568 suggests a likely relationship. Figure 3 shows that average costs converge when recalculated using the visits per FTE of the most 'efficient' hospital (U). Differences in capacity use have little bearing on average cost variation, although there are significant reductions for all facilities in average costs under the $100 \%$ capacity use assumption. Econo-

Table II. Hypothesised impact of various factors on unit cost, and methods for assessment of unit cost variation

\begin{tabular}{|c|c|c|c|}
\hline Factor & Hypothesised impact on unit cost & Methods for assessment & $\begin{array}{l}\text { Used in this } \\
\text { study }\end{array}$ \\
\hline X-efficiency & $\begin{array}{l}\text { Wastage ( } \mathrm{x} \text {-inefficiency) increases average and } \\
\text { marginal cost }\end{array}$ & $\begin{array}{l}\text { Data envelopment analysis (inputs: average monthly staff } \\
\text { costs and total cost of capital stock; output: average } \\
\text { activity data) } \\
\text { Tabulate staff ratios with unit cost } \\
\text { Recalculate unit costs using staff ratio of most productive } \\
\text { health facility }\end{array}$ & $\begin{array}{l}\text { Yes } \\
\text { Yes }\end{array}$ \\
\hline $\begin{array}{l}\text { Returns to the } \\
\text { variable factor }\end{array}$ & $\begin{array}{l}\text { The presence of spare capacity increases average } \\
\text { cost }\end{array}$ & $\begin{array}{l}\text { Tabulate monthly throughput against unit cost } \\
\text { Re-estimate costs assuming } 80 \% \text { and } 100 \% \text { capacity use }\end{array}$ & $\begin{array}{l}\text { Yes } \\
\text { Yes }\end{array}$ \\
\hline Economies of scale & $\begin{array}{l}\text { Larger providers may use resources more } \\
\text { productively, thus lowering average cost }\end{array}$ & $\begin{array}{l}\text { Tabulate health provider size against unit cost } \\
\text { Tabulate \% overhead cost against unit cost }\end{array}$ & $\begin{array}{l}\text { Yes } \\
\text { Yes }\end{array}$ \\
\hline Input mix & $\begin{array}{l}\text { Greater resource intensity increases average and } \\
\text { marginal cost }\end{array}$ & Tabulate resource intensity ratios against prices & No \\
\hline \multirow[t]{2}{*}{ Case mix } & $\begin{array}{l}\text { More severely ill patients increases average and } \\
\text { marginal cost }\end{array}$ & Tabulate risk conditions against unit cost & No \\
\hline & & Tabulate morbidity levels against unit cost & No \\
\hline \multirow[t]{2}{*}{ Costing methodology } & $\begin{array}{l}\text { Inappropriate methodology reduces the accuracy } \\
\text { of average and marginal cost }\end{array}$ & Critically evaluate costing methods & Yes \\
\hline & & Examine differences in costing methods & Yes \\
\hline Uncertainty & $\begin{array}{l}\text { Affects the size and confidence intervals of } \\
\text { average and marginal cost (either direction) }\end{array}$ & One-way and multi-way sensitivity analysis & No \\
\hline
\end{tabular}




\begin{tabular}{|c|c|c|c|c|c|c|c|c|c|c|c|c|c|}
\hline \multirow{2}{*}{$\begin{array}{l}\text { Country, healthcare } \\
\text { provider (letter) and } \\
\text { trial arm average }\end{array}$} & \multicolumn{2}{|c|}{$\begin{array}{l}\text { Outpatient ANC } \\
\text { average visits }\end{array}$} & \multicolumn{5}{|c|}{ Inpatient ANC ALOS (days) } & \multicolumn{2}{|c|}{ Deliveries (\%) } & \multicolumn{2}{|c|}{$\begin{array}{l}\text { Postpartum ALOS } \\
\text { (days) }\end{array}$} & \multicolumn{2}{|c|}{$\begin{array}{l}\text { Neonatal ICU } \\
\text { ALOS (days) }\end{array}$} \\
\hline & mean & median & \multicolumn{2}{|c|}{ All inpatients ${ }^{a}$} & $\mathrm{LR}^{\mathrm{a}}$ & $\mathrm{HR}^{\mathrm{a}}$ & ALL & VD & CS & \multirow[t]{2}{*}{ VD } & \multirow[t]{2}{*}{ CS } & \multirow[t]{2}{*}{ mean } & \multirow[t]{2}{*}{ ALL } \\
\hline Cuba & & & & & & & & & & & & & \\
\hline A & 7.6 & 5 & & & 12.2 & 11.7 & 1.76 & 75 & 25 & 2.9 & 5.7 & 10.4 & 0.49 \\
\hline B & 7.4 & 5 & & & 15.6 & 11.3 & 2.15 & 76 & 24 & 3.1 & 6.2 & 12.6 & 0.75 \\
\hline$D$ & 7.8 & 6 & & a & 10.6 & 14 & 1.81 & 82 & 18 & 3.3 & 5.5 & 14.4 & 0.69 \\
\hline$E$ & 7.5 & 6 & & 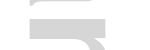 & 16.3 & 10.5 & 2.22 & 77 & 23 & 3 & 6.8 & 11.5 & 0.61 \\
\hline $\mathrm{F}$ & 7.3 & 5 & & & 17.3 & 9.5 & 2.56 & 74 & 26 & 3.8 & 6.3 & 13.8 & 1.17 \\
\hline $\begin{array}{l}\text { Average in intervention } \\
\text { arm }\end{array}$ & 7.5 & 6 & & & 13.6 & 10.9 & 1.95 & 77 & 23 & 3.2 & 6.0 & 12.0 & 0.69 \\
\hline $\mathrm{K}$ & 13.0 & 12 & & & 15 & 6.7 & 1.93 & 76 & 24 & 3.2 & 5.7 & 11.0 & 0.81 \\
\hline$G$ & 13.1 & 13 & & & 13.3 & 8.0 & 1.5 & 77 & 23 & 3.1 & 6.4 & 10.2 & 0.65 \\
\hline J & 13.3 & 13 & & & 14.9 & 7.1 & 1.77 & 77 & 23 & 3.1 & 6 & 9.8 & 0.55 \\
\hline L & 13.6 & 13 & & & 8.5 & 8.4 & 1.06 & 77 & 23 & 2.9 & 6 & 14.1 & 0.76 \\
\hline $\mathrm{H}$ & 12.4 & 12 & & & 14.1 & 8.7 & 0.94 & 79 & 21 & 3.3 & 5.2 & 9.6 & 0.65 \\
\hline $\begin{array}{l}\text { Average in control arm } \\
\text { Thailand }\end{array}$ & 13.1 & 13 & & 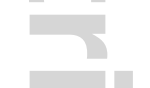 & 13.1 & 8.3 & 1.50 & 77 & 23 & 3.0 & 5.8 & 10.7 & 0.64 \\
\hline$N$ & 4.7 & 4 & 3.4 & 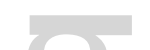 & & & 0.09 & 87 & 3 & 1.40 & 2.26 & 7.88 & 0.11 \\
\hline$P$ & 4.1 & 4 & 2.5 & ( & & & 0.08 & 94 & 6 & 2.11 & 3.96 & 4.79 & 0.30 \\
\hline$Q$ & 4.6 & 4 & 2.0 & & & & 0.02 & 91 & 9 & 1.79 & 3.83 & 11.89 & 0.59 \\
\hline $\mathrm{R}$ & 4.5 & 4 & 2.3 & 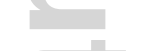 & & & 0.09 & 95 & 5 & 1.95 & 1.53 & 6.17 & 0.18 \\
\hline S & 4.4 & 4 & 2.9 & $\sqrt{-5}$ & & & 0.10 & 95 & 5 & 1.53 & 2.48 & 3.94 & 0.13 \\
\hline $\mathrm{T}$ & 4.2 & 4 & 4.0 & $x^{2}$ & & & 0.16 & 97 & 3 & 1.69 & 2.05 & 2.78 & 0.08 \\
\hline $\begin{array}{l}\text { Average in intervention } \\
\text { arm }\end{array}$ & 4.4 & 4 & 2.9 & & & & 0.09 & 93 & 5 & 1.75 & 2.69 & 6.24 & 0.23 \\
\hline U & 6.2 & 6 & 1.8 & & & & 0.02 & 96 & 4 & 1.73 & 3.32 & 5.14 & 0.33 \\
\hline v & 6.4 & 6 & 2.0 & & & & 0.01 & 95 & 5 & 1.43 & 4.65 & 3.40 & 0.13 \\
\hline Y & 8.1 & 8 & 4.2 & & & & 0.11 & 93 & 7 & 1.92 & 3.70 & 12.68 & 0.50 \\
\hline z & 6.6 & 7 & 3.4 & & & & 0.14 & 93 & 7 & 1.50 & 4.95 & 5.16 & 0.12 \\
\hline Average in control arm & 7.1 & 7 & 2.8 & & & & 0.08 & 95 & 5 & 1.52 & 3.28 & 7.01 & 0.28 \\
\hline
\end{tabular}

$\mathbf{A L L}=$ the average over all births included in trial data set; $\mathbf{A L O S}=$ average length of stay; $\mathbf{A N C}=$ antenatal care; $\mathbf{C S}=$ caesarean section; $\mathbf{H R}=$ high-risk women; $\mathbf{I C U}=$ intensive care unit; LR = low-risk women; VD = vaginal delivery. 


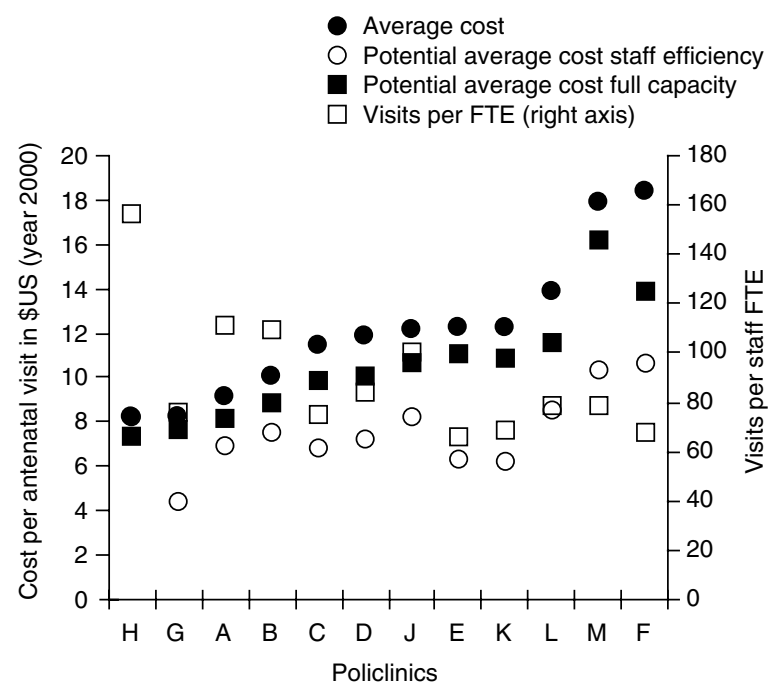

Fig. 2. Average cost, 'potential' average cost and staff efficiency in antenatal clinics in Cuba. FTE = full-time equivalent.

mies of scale also do not appear to be present to the same degree as in Cuba (correlation coefficient -0.251 ).

\section{Case Cost Variation}

In both Cuba and Thailand there was considerable heterogeneity in CPP between health facilities within each trial arm, as shown in figure 4 and figure 5 . In Cuba, the differences between policlinics in ACPP could be partly explained by differences in use of inpatient services (see table III). For example, the high ACPP in ' $F$ ' was partly explained by higher than average antenatal and neonatal stay. Also, high average costs for antenatal care in some policlinics partly explained the high ACPP observed in these same policlinics (e.g. F and M).

In Thailand, there appears to be no strong relationship between average inpatient days per woman and ACPP. The low ACPP in district hospital ' $\mathrm{Z}$ ' was partly due to the low average rates of health service use for all types of care, especially postpartum care. In ' $\mathrm{P}$ ', there was a higher than average postpartum stay, but ACPP was low. There is only limited correlation between outpatient visits or outpatient average cost with ACPP. The high ACPP in ' $Y$ ' was partly explained by the high antenatal visits and high average cost for caesarean section, but average costs of antenatal and other health service use measures were in the middle range. On the other hand, some hospitals with high average costs ( $\mathrm{T}$ and $\mathrm{Z}$ ) only had mid-range ACPP, thus suggesting unexplained variation in ACPP. Furthermore, the causes of the low ACPP in ' $N$ ' and ' $\mathrm{P}$ ' were not apparent from this analysis. The analysis did reveal that one important determinant of ACPP in Thailand was the rate of referral to secondary hospitals for delivery or inpatient care, where aver- age costs were significantly higher. The average referral rate for all hospitals was $14.5 \%$, but individual hospitals varied between $\sim 1 \%(\mathrm{~N}$ and $\mathrm{Z})$ and $>25 \%(\mathrm{Q}, \mathrm{Y}$ and $\mathrm{V})$.

\section{Discussion}

This article presented the results from a detailed comparison and analysis of costs in two of four of the countries taking part in a multicountry, multicentre RCT. A framework for cost analysis was outlined and justified, aiming to increase the consistency and comprehensiveness of the cost analysis. Using this framework, not only were overall costs per patient analysed in terms of total cost and incremental cost, but also the components of these were analysed in detail. Such an analysis of cost components allowed a more in-depth analysis and understanding of the aggregated cost data, such as CPP or the incremental costs between interventions.

The results of the analysis have shown that an understanding of the cost differences at the overall level can only be complete once an in-depth microeconomic analysis has been conducted, taking into account the microeconomic and health determinants of costs. Several important findings were presented on cost behaviour in the study settings. It is expected that this framework for cost analysis can be further refined and tested with the help of different data sets, not only from different countries, but also from different areas of healthcare. Ultimately, a further refined framework could be used as a basis for cost analysis in any country and in any field of healthcare.

Given the few studies in the literature that have examined cost differences in the context of a multicentre, multinational trial, the analysis presented in this study could be argued to be among the first of its kind. The framework developed and the analyses

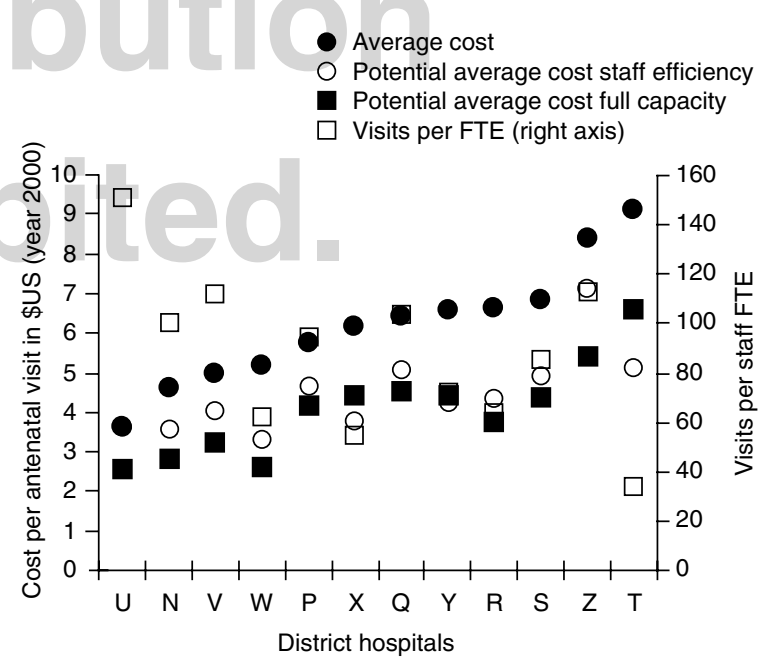

Fig. 3. Average cost, 'potential' average cost and staff efficiency in antenatal clinics in Thailand. FTE = full-time equivalent. 


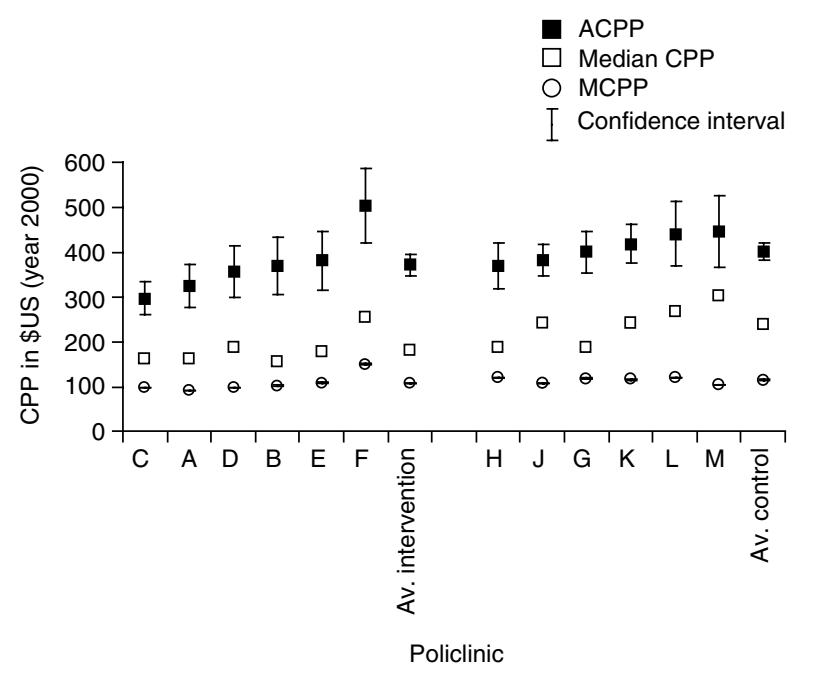

Fig. 4. Average and marginal cost per pregnancy in Cuba. ACPP = average CPP; Av. control = average in control trial arm; Av. intervention = average in intervention trial arm; $\mathbf{C P P}=$ cost per pregnancy; $\mathbf{M C P P}=$ marginal CPP.

conducted have generated some important conclusions concerning the major factors that determine costs. The most important of these was the use of health personnel, analysed by examining returns to the variable factor, technical efficiency, and the link between staff productivity and unit cost. Unit cost contributions of other resources, such as drugs, materials and equipment, also varied significantly between health facilities. For fixed items, such as equipment and buildings, economies of scale were found to explain part of the variation. Different types of health service use were found to vary according to the antenatal care model being applied, the illnesses of patients and specific provider practices.

Major findings of the cost study that deserve further emphasis are the extent and causes of within-arm cost variation. These highlight the question of the validity of comparing trial arms when such large cost variations were observed within arms. There is no simple answer. In general, the CPP variations within a trial arm were not so much related to the 'intervention' of reducing the number of antenatal visits and instead to other factors unrelated to the 'intervention'. The first factor is the variation in unit cost between health facilities, irrespective of trial arm. These variations were related more to the facility efficiency and level of throughput than to the intervention itself. The second factor is the variation in inpatient health service use between facilities, which was found to be largely related to unexplainable (random) variations in practice between facilities, as well as some link to patient case mix. Together, these factors caused considerable CPP variations within trial arms in both Cuba and Thailand.

\section{Conclusions}

The literature indicates a concern in the research community about the existence of cost variations between healthcare settings. ${ }^{[1,3-7]}$ This limits the generalisability of costs and cost-effectiveness ratios between settings. However, to date there exists no comprehensive and pre-defined toolkit for analysing and understanding costs. This article has outlined and applied an analytical framework and cost typology for disaggregating costs into their component parts, and applied a range of cost analysis techniques to understand the determinants of cost.

The importance of such an analytical framework and a cost analysis toolkit was underlined by the findings presented in this article. First, cost variations or differences at the aggregate level cannot be understood without an understanding of the separate components of cost and the cost variations that exist at this disaggregated level. This was demonstrated by the understanding gained by the cost analysis conducted on the components of aggregate cost. Second, variations between the two countries in the study were found in cost determinants, such as the existence of economies of scale or the relationship between staff productivity and unit cost. Third, even within a country, there can be large uncertainty when making cost predictions based on the established cost determinants, due to numerous cost determinants that take on different significance in different settings. Fourth, in some cases a considerable amount of cost variation remained unexplained, suggesting that some cost determinants were either not examined at all, or that the analytical tools were inadequate to examine identi-

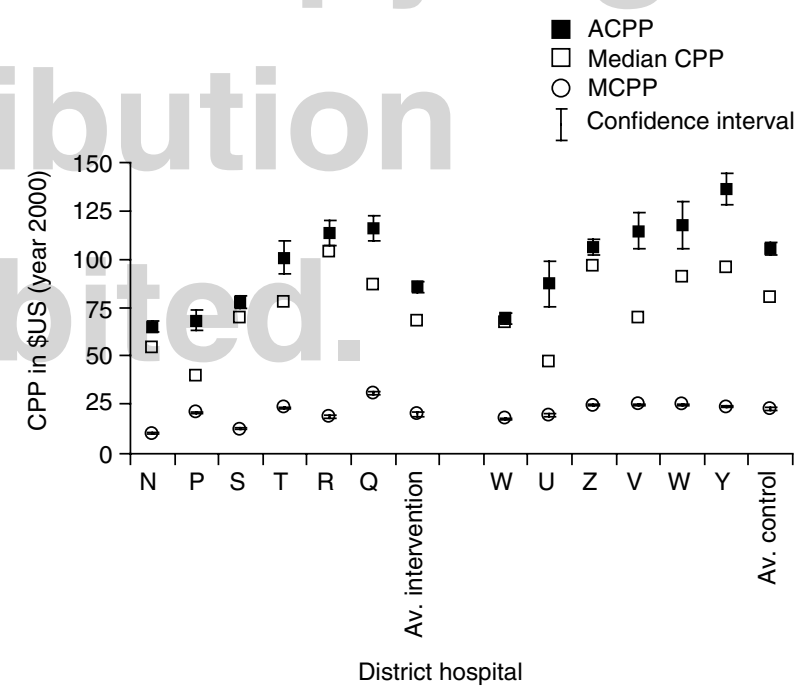

Fig. 5. Average and marginal cost per pregnancy in Thailand. ACPP = average CPP; Av. control = average in control trial arm; Av. intervention $=$ average in intervention trial arm; $\mathbf{C P P}=$ cost per pregnancy; $\mathbf{M C P P}=$ marginal CPP. 
fied sources of cost variation. Together, these four major findings point to the urgency of further development of the framework and toolkit we have outlined. This would aid economic analysts in understanding costs, and would help them think through the implications of cost variations for economic study design and policy making.

In terms of economic study design, the conclusions from this study are clear. The high level of cost variation between study centres within the same country raises important concerns for the randomisation process and for sample size selection. Concerning randomisation, important economic differences between clinics participating in a multicentre study suggests that it may be necessary to match clinics by key economic characteristics. If this is not done, and more 'expensive' clinics get randomised to one trial arm, for example, this would lead to economically unreliable results. Concerning sample size selection, the finding from this study is that omission of one high-cost health facility from one arm and one low-cost health facility from the other arm could have altered the overall cost-effectiveness conclusions. Therefore, a sufficient sample size for the costing component is of primary importance to ensure study results are not overly influenced by outliers, or by differences not related to the intervention.

In terms of policy implications, national policy makers will be interested to know whether the results of the study are generalisable from the study site to other similar settings within the same country. Given the variability in cost outcomes between the 12 health facilities in Cuba and Thailand, it cannot be said with confidence whether CPP (and components of CPP) would be the same throughout the country. Factors that influence the generalisability of the cost findings include, most importantly, (a) whether the rest of the country provides care in a similar way to the control group in the trial (and therefore has similar unit costs and health service use); (b) whether the intervention (the new antenatal care programme) would be implemented in a similar way to the trial; and (c) whether the patient case mix and patient behaviour (e.g. antenatal clinic attendance practices) are similar in other settings. Furthermore, cost determinants such as staffing levels and productivity, drug prescription practices and levels, and health facility population coverage should be compared between settings before making generalisations.

\section{Acknowledgements}

The research study was conducted while two study authors - Guy Hutton and Julia Fox-Rushby - were based at the Health Policy Unit, London School of Hygiene and Tropical Medicine (LSHTM). We would like to thank colleagues at LSHTM for their input to this study, in particular Professor Anne
Mills and Professor Charles Normand for their contributions to the study design and interpretation of results. Tom Marshall contributed to the statistical analyses.

This research study was funded by the UK Department for International Development, for the work in Cuba and Thailand. However, the Department for International Development can accept no responsibility for any information provided or views expressed.

We are indebted to many for the success of our study. We especially thank the trial lead investigator José Villar (HRP, WHO) as well as the members of the steering committee for the WHO trial, and Craig Lissner (WHO) who helped develop and justify the plan for the economic study and who facilitated its implementation. We extend our appreciation to the principal investigators in Cuba (Professor Ubaldo Farnot) and Thailand (Professor Pisake Lumbiganon) for their assistance in conducting the economic study. In each country, local managers, clinicians and women patients assisted our data collection.

The authors have no conflicts of interest that are directly relevant to the content of this study.

\section{References}

1. Spath HM, Carrere MO, Fervers B, et al. Analysis of the eligibility of published economic evaluations for transfer to a given health care system: methodological approach and application to the French health care system. Health Policy 1999; 49: 161-77

2. Madden L, Hussey R, Mooney G, et al. Public health and economics in tandem: programme budgeting, marginal analysis and priority setting in practice. Health Policy 1995; 33: 161-8

. Drummond MF, Bloom BS, Carrin G, et al. Issues in the cross-national assessment of health technology. Int J Technol Assess Health Care 1992; 8: 671-82

4. Briggs A, Sculpher M, Buxton M. Uncertainty in the economic evaluation of health care technologies: the role of sensitivity analysis. Health Econ 1994; 3: 95-104

5. Jefferson T, Mugford M, Graym A, et al. An exercise on the feasibility of carrying out secondary economic analyses. Health Econ 1996; 5: 155-65

6. O'Brien B. A tale of two (or more) cities: geographical transferability of pharmacoeconomic data. Am J Manag Care 1997; 3 Suppl.: S33-9

7. Bryan S, Brown J. Extrapolation of cost-effectiveness information to local settings. J Health Serv Res Policy 1998; 3: 108-12

8. Udvarhelyi IS, Colditz GA, Rai A, et al. Cost-effectiveness and cost-benefit analyses in the medical literature: are the methods being used correctly? Ann Intern Med 1992; 116: 238-44

9. Gerard K, Mooney G. QALY league tables: handle with care. Health Econ 1993; 2: 59-64

10. Mason J, Drummond M. Reporting guidelines for economic studies. Health Econ $1995 ; 4: 85-94$

11. Walker D, Fox-Rushby JA. Economic evaluation of communicable disease interventions in developing countries: a critical review of the published literature. Health Econ 2000; 9: 681-98

12. Buxton MJ, Drummond MF, Van Hout BA, et al. Modelling in economic evaluation: an unavoidable fact of life. Health Econ 1997; 6: 217-27

13. Heyse J, Cook J, Carides G. Statistical considerations in analysing health care resource utilization and cost data. In: McGuire A, Drummond M, editors. Economic evaluation in health care: merging theory with practice. New York: Oxford University Press, 2001

14. Brouwer W, Rutten F, Koopmanschap M. Costing in economic evaluations. In: McGuire A, Drummond M, editors. Economic evaluation in health care: merging theory with practice. New York: Oxford University Press, 2001

15. Drummond M, Pang F. Transferability of economic evaluation results. In: McGuire A, Drummond M, editors. Economic evaluation in health care: merging theory with practice. New York: Oxford University Press, 2001 
16. De Jonghe E, Murray C, Chum H, et al. Cost-effectiveness of chemotherapy for sputum smear-positive pulmonary tuberculosis in Malawi, Mozambique and Tanzania. Int J Health Plann Manage 1994; 9: 151-81

17. Schulman K, Buxton M, Glick H, et al. Results of the economic evaluation of the FIRST study: a multinational prospective economic evaluation. FIRST Investigators: Flolan International Randomized Survival Trial. Int J Technol Assess Health Care 1996; 12: 698-713

18. Menzin J, Oster G, Davies L, et al. A multinational economic evaluation of rhDNase in the treatment of cystic fibrosis. Int J Technol Assess Health Care 1996; 12: 52-61

19. Villar J, Ba'aqeel H, Piaggio G, et al. WHO antenatal care randomised controled trial for the evaluation of a new model of routine antenatal care trial. Lancet 2001; 357: 1551-64

20. Schulman K, Burke J, Drummond M, et al. Resource costing for multinational neurologic clinical trials: methods and results. Health Econ 1998; 7: 629-38

21. Jonsson B, Johannesson M, Kjekshus J, et al. Cost-effectiveness of cholesterol lowering: results from the Scandinavian simvastatin survival study $(4 \mathrm{~S})$. Eur Heart J 1996; 17: 1001-7

22. Glick H, Willke R, Polsky D, et al. Economic analysis of Tirilazad Mesylate for aneurysmal subarachnoid hemorrhage. Int J Health Plann Manage 1998; 14: $145-60$

23. Dasbach E, Rich M, Segal R, et al. The cost-effectiveness of losartan versus captopril in patients with symptomatic heart failure. Cardiology 1999; 91: 189-94

24. Jonsson B, Weinstein M. Economic evaluation alongside multinational trials: study considerations for GUSTO IIb. Int J Technol Assess Health Care 1997; 13 49-58

25. Wimo A, Winblad B, Engedal K, et al. An economic evaluation of donepezil in mild to moderate Alzheimer's disease: results of a 1-year, double-blind, randomized trial. Dement Geriatr Cogn Disord 2003; 15: 44-54

26. Lumbiganon P, Bergso $\mathrm{P}$, Ba'aqeel $\mathrm{H}$, et al., editors. A randomised controlled trial for the evaluation of a new antenatal care model. Paediatr Perinat Epidemiol 1998; 12 Suppl. 2: 1-164

27. Mugford M, Hutton G, Fox-Rushby J. Methods for the economic evaluation alongside a multicentre trial in developing countries: a case study from the WHO antenatal care randomised controlled trial. Paediatr Perinat Epidemiol 1998; 12: 75-97

28. Donaldson C. The state of the art of costing health care for economic evaluation. Community Health Stud 1990; 14: 341-56
29. Rovira J. Standardising economic appraisal of health technology in the European Community. Soc Sci Med 1994; 38: 1675-8

30. Baladi J-F. A guidance process for the costing process. Ottawa: Canadian Coordinating Office for Health Technology Assessment, 1996

31. Gold MR, Siegel JE, Russell LB, et al. Cost-effectiveness in health and medicine. New York: Oxford University Press, 1996

32. Drummond MF, O'Brien B, Stoddart GL, et al. Methods for the economic evaluation of health care programmes. New York: Oxford University Press, 1997

33. Galvez A, Alvarez M, Sanabria G, et al. Economic evaluation alongside an antenatal care trial in developing countries. Report on Cuba [research report no. 12]. Norwich: School of Health Policy and Practice, University of East Anglia, 2000

34. Thinkhamrop J, Thinkhamrop B, Kuchaisit C, et al. A study on the costs of antenatal care alongside the World Health Organization trial in Thailand [research report no. 10]. Norwich: School of Health Policy and Practice, University of East Anglia, 2000

35. Borghi J, Bastus S, Belizan M, et al. Costs of antenatal and related care in Argentina: a cost-minimisation analysis of the new WHO antenatal care package. London: London School of Hygiene and Tropical Medicine, 2000

36. Smith S, Fox-Rushby J, Hutton G, et al. An economic evaluation of the costs of the new WHO programme of antenatal care in Saudi Arabia. London: London School of Hygiene and Tropical Medicine, 2001

37. Langer A, Villar J, Romero M, et al. Are women and providers satisfied with antenatal care? Views on a standard and a simplified, evidence-based model of care in four developing countries. BMC Womens Health 2002; 2: 7-16

38. Langer A, Nigenda G. Conceptual basis and methodology for the evaluation of women's and providers' perception of the quality of antenatal care in the WHO antenatal care randomised controlled trial. Paediatr Perinat Epidemiol 1998; 12 : $98-115$

Correspondence and offprints: Dr Guy Hutton, Swiss Centre for International Health, Swiss Tropical Institute, Socinstrasse 57, Basel, 4002, Switzerland.

E-mail: guy.hutton@unibas.ch 